\title{
KETAKSAMAAN HERMITE-HADAMARD TERHADAP INTEGRAL RIEMANN-STIELTJES
}

\author{
Denny Ivanal Hakim
}

Departemen Matematika Institut Teknologi Bandung Bandung 40132, Indonesia dnny_hkm@yahoo.com

\section{Hendra Gunawan}

Departemen Matematika Institut Teknologi Bandung Bandung 40132, Indonesia hgunawan@math.itb.ac.id

\begin{abstract}
The Hermite-Hadamard inequality is an inequality for convex functions that gives an estimate for the integral mean value of a convex function on a closed interval by its value at the middle of interval and the average of its values at the endpoints. The Hermite-Hadamard inequality can be generalized by using the RiemannStieltjes integral mean value. An application of the Hermite-Hadamard inequality with respect to Riemann-Stieltjes integral for estimating the power mean of $n$ positive real numbers by the aritmethic mean is given at the end of discussion.
\end{abstract}

Keywords: Convex function, Hermite-Hadamard inequality, Riemann-Stieltjes integral mean value

ABSTRAK. Ketaksamaan Hermite-Hadamard adalah ketaksamaan untuk fungsi konveks yang memberikan taksiran nilai rata-rata integral suatu fungsi konveks pada interval tutup dengan nilai fungsi di titik tengah interval dan nilai rata-rata fungsi di kedua ujung interval. Ketaksamaan Hermite-Hadamard dapat diperumum dengan menggunakan nilai rata-rata integral Riemann Stieltjes. Suatu aplikasi ketaksamaan Hermite-Hadamard terhadap integral Riemann-Stieltjes untuk penaksiran rataan pangkat dari $n$ bilangan real positif dengan rataan aritmatika diberikan pada bagian akhir pembahasan.

Kata kunci: Fungsi konveks, ketaksamaaan Hermite-Hadamard, nilai rata-rata integral Riemann-Stieltjes

\section{PENDAHULUAN}

Misalkan $I$ adalah interval bilangan real. Fungsi $f: I \rightarrow \mathbb{R}$ disebut fungsi konveks jika

$$
f(\lambda x+(1-\lambda) y) \leq \lambda f(x)+(1-\lambda) f(y)
$$

untuk setiap $x, y \in I$ dan $\lambda \in[0,1]$. 
Fungsi konveks mempunyai tafsiran geometris bahwa grafik fungsi dari semua titik pada interval $(x, y)$ selalu berada di bawah tali busur yang menghubungkan titik $(x, f(x))$ dan $(y, f(y))$. Secara formal, hal ini dinyatakan dalam lema berikut:

Lema 1.1 Misalkan $f:[a, b] \rightarrow \mathbb{R}$ adalah fungsi konveks. Maka untuk setiap $x_{1}, x_{2}, x_{3} \in[a, b]$ yang memenuhi $x_{1}<x_{2}<x_{3}$ berlaku

$$
f\left(x_{2}\right) \leq f\left(x_{1}\right)+\frac{f\left(x_{3}\right)-f\left(x_{1}\right)}{x_{3}-x_{1}}\left(x_{2}-x_{1}\right)
$$

Dengan mengatur ulang suku-suku ketaksamaan (1) dapat diperoleh

$$
\frac{f\left(x_{2}\right)-f\left(x_{1}\right)}{x_{2}-x_{1}} \leq \frac{f\left(x_{3}\right)-f\left(x_{1}\right)}{x_{3}-x_{1}} \leq \frac{f\left(x_{3}\right)-f\left(x_{2}\right)}{x_{3}-x_{2}}
$$

Pembuktian ketaksamaan (1) dan (2) dapat dilihat di (Roberts dan Varberg, 1975). Ketaksamaan lain yang dapat dibuktikan secara langsung dari definisi fungsi konveks dapat dilihat di (Mitrinovic, dkk, 1993). Dari ketaksamaan (2) dapat diperoleh salah satu sifat penting dari fungsi konveks yaitu untuk suatu titik pada kurva fungsi konveks, gradien tali busur yang menghubungkan titik tersebut dengan titik lain pada kurva selalu monoton naik. Hal ini dinyatakan dalam teorema berikut:

Teorema 1.2. Misalkan $f:[a, b] \rightarrow \mathbb{R}$ adalah fungsi konveks dan $c \in[a, b]$. Definisikan fungsi $s_{c}(x):[a, b] \backslash\{c\} \rightarrow \mathbb{R}$ dengan aturan $s_{c}(x)=\frac{f(x)-f(c)}{x-c}$. Maka fungsi $s_{c}(x)$ monoton naik pada $[a, b] \backslash\{c\}$.

Sebagai akibat dari teorema ini adalah fungsi $f$ memiliki turunan sepihak pada $(a, b)$ dan untuk setiap $x, y \in(a, b)$ yang memenuhi $x<y$ berlaku

$$
f_{-}^{\prime}(x) \leq f_{+}^{\prime}(x) \leq \frac{f(y)-f(x)}{y-x} \leq f_{-}^{\prime}(y) \leq f_{+}^{\prime}(y)
$$

Pembuktian Teorema 1.2 dan ketaksamaan (3) dapat dilihat di (Roberts dan Varberg, 1975). Akibat dari eksistensi turunan sepihak fungsi konveks $f$ pada $(a, b)$ adalah fungsi $f$ kontinu pada $(a, b)$. Lebih jauh, nilai $f$ pada kedua ujung 
interval $[a, b]$ dapat dimodifikasi sehingga $f$ kontinu pada $[a, b]$ yang berakibat keterintegralan $f$ pada $[a, b]$. Salah satu ketaksamaan fungsi konveks yang terkait dengan integralnya adalah ketaksamaan Hermite-Hadamard. Ketaksamaan ini memberikan taksiran nilai rata-rata integral suatu fungsi konveks dengan nilai fungsi di titik tengah interval dan nilai rata-rata fungsi di kedua ujung interval. Hal ini dinyatakan dalam teorema berikut:

Teorema 1.3. Jika $f:[a, b] \rightarrow \mathbb{R}$ adalah fungsi konveks, maka

$$
f\left(\frac{a+b}{2}\right) \leq \frac{1}{b-a} \int_{a}^{b} f(x) d x \leq \frac{f(a)+f(b)}{2}
$$

Pembuktian Teorema 1.3 dapat dilihat di (Niculescu dan Persson, 2006). Ekuivalensi ketaksamaan Hermite-Hadamard dan ketaksamaan Chebyshev dibahas dalam (Niculescu dan Pecaric, 2010). Titik $x=\frac{a+b}{2}$ dapat dipandang sebagai nilai rata-rata integral fungsi $h(x)=x$ pada selang $[a, b]$. Ternyata dengan meninjau nilai rata-rata integral Riemann-Stieltjes terhadap fungsi $g$ yang monoton naik pada $[a, b]$ dan $g(b)-g(a)=1$, ketaksamaan (4) dapat diperumum menjadi ketaksamaan Hermite-Hadamard terhadap integral RiemannStieltjes.

\section{PEMBAHASAN}

\subsection{Nilai rata-rata Integral Riemann-Stieltjes.}

Berikut ini diberikan definisi nilai rata-rata integral Riemann-Stieltjes:

Definisi 2.1. Misalkan $g:[a, b] \rightarrow \mathbb{R}$ adalah fungsi monoton naik dan memenuhi $g(b)-g(a)>0$. Misalkan fungsi $f:[a, b] \rightarrow \mathbb{R}$ terintegralkan RiemannStieltjes terhadap fungsi $g$. Nilai rata-rata integral Riemann-Stieltjes $f$ terhadap $g$ didefinisikan sebagai

$$
M(f)=\frac{1}{g(b)-g(a)} \int_{a}^{b} f(x) d g(x)
$$

Jika $g(x)=x$, maka $M(f)=\frac{1}{b-a} \int_{a}^{b} f(x) d x$ yaitu nilai rata-rata integral Riemann yang biasa dikenal. Khususnya, untuk $f(x)=x$ diperoleh $M(f)=\frac{a+b}{2}$ yang merupakan titik tengah interval $[a, b]$. 
Dari fungsi $g:[a, b] \rightarrow \mathbb{R}$ yang monoton naik dan memenuhi $g(b)-g(a)=1$ selalu dapat didefinisikan suatu fungsi $u$ yang bergantung dari $g$ dan bernilai tak negatif pada $[a, b]$. Hal ini dinyatakan dalam lema berikut:

Lema 2.2. Misalkan $g:[a, b] \rightarrow \mathbb{R}$ adalah fungsi monoton naik dan memenuhi $g(b)-g(a)=1$. Definisikan $u:[a, b] \rightarrow \mathbb{R}$ dengan aturan

$$
u(x)=[g(x)-g(b)] \int_{a}^{x} t d g(t)+[g(x)-g(a)] \int_{x}^{b} t d g(t)
$$

untuk setiap $x \in[a, b]$. Maka, $u(x) \geq 0$ pada $[a, b]$.

Bukti: Ambil $x \in[a, b]$ sebarang. Karena $\int_{a}^{x} t d g(a)=0$ dan $\int_{x}^{b} t d g(b)=0$, maka

$$
\begin{aligned}
u(x)=\quad[g(x)-g(b)]\left[\int_{a}^{x} t d g(t)-\int_{a}^{x} t d g(a)\right] \\
+[g(x)-g(a)]\left[\int_{x}^{b} t d g(t)-\int_{x}^{b} t d g(b)\right] \\
=\quad[g(x)-g(b)] \int_{a}^{x} t d(g(t)-g(a)) \\
+[g(x)-g(a)] \int_{x}^{b} t d(g(t)-g(b))
\end{aligned}
$$

Dengan menggunakan teknik integral parsial diperoleh

$$
\begin{aligned}
u(x)= & {\left.[g(x)-g(b)][t(g(t)-g(a))]_{a}^{x}-\int_{a}^{x}(g(t)-g(a)) d t\right] } \\
& +[g(x)-g(a)]\left[[t(g(t)-g(b))]_{x}^{b}-\int_{x}^{b}(g(t)-g(b)) d t\right] \\
= & {[g(b)-g(x)] \int_{a}^{x}(g(t)-g(a)) d t } \\
& +[g(x)-g(a)] \int_{x}^{b}(g(b)-g(t)) d t
\end{aligned}
$$

Karena fungsi $g$ monoton naik pada $[a, b]$, maka untuk setiap $g(x)-g(a) \geq 0$ dan $g(b)-g(x) \geq 0$. Akibatnya, berdasarkan sifat positif integral dapat disimpulkan bahwa $u(x) \geq 0$ pada $[a, b]$. 
Kekontinuan suatu fungsi menjamin eksistensi integral Riemann-Stieltjes dari fungsi tersebut terhadap fungsi $u$ yang didefinisikan pada lema sebelumnya. Lebih jauh, integral fungsi tersebut terhadap $u$ dapat dinyatakan sebagai integral terhadap fungsi $g$. Hal ini dinyatakan dalam lema berikut:

Lema 2.3. Misalkan $g:[a, b] \rightarrow \mathbb{R}$ adalah fungsi monoton naik dengan $g(b)-$ $g(a)=1 \quad$ dan $\quad u(x)=[g(x)-g(b)] \int_{a}^{x} t d g(t)+[g(x)-g(a)] \int_{x}^{b} t d g(t)$ untuk setiap $x \in[a, b]$. Misalkan $x_{g}=\int_{a}^{b} x d g(x)$ dan $v:[a, b] \rightarrow \mathbb{R}$ adalah fungsi yang kontinu, maka

$$
\int_{a}^{b} v(x) d u(x)=\int_{a}^{b} v(x)\left(x_{g}-x\right) d g(x)
$$

Bukti: Ambil $x \in[a, b]$ sebarang, maka

$$
\begin{aligned}
u(x) & =(g(x)-g(b)+g(a)-g(a)) \int_{a}^{x} t d g(t)+(g(x)-g(a)) \int_{x}^{b} t d g(t) \\
& =[g(x)-g(a)]\left[\int_{a}^{x} t d g(t)+\int_{x}^{b} t d g(t)\right]-[g(b)-g(a)] \int_{a}^{x} t d g(t) \\
& =\left(\int_{a}^{x} d g(t)\right)\left(\int_{a}^{b} s d g(s)\right)-\left(\int_{a}^{b} d g(s)\right)\left(\int_{a}^{x} t d g(t)\right) \\
& =\int_{a}^{x} \int_{a}^{b}(s-t) d g(s) d g(t)
\end{aligned}
$$

Akibatnya,

$$
\int_{a}^{b} v(x) d u(x)=\int_{a}^{b} v(x) \int_{a}^{b}(s-x) d g(s) d g(x)=\int_{a}^{b} v(x)\left(x_{g}-x\right) d g(x)
$$

Selanjutnya Lema 2.2 dan 2.3 ini digunakan untuk pembuktian ketaksamaan Hermite-Hadamard terhadap integral Riemann-Stieltjes .

\subsection{Ketaksamaan Hermite-Hadamard terhadap Integral Riemann-Stieltjes.}

Ketaksamaan Hermite-Hadamard terhadap integral Riemann-Stieltjes dinyatakan dalam teorema berikut:

Teorema 2.4. Misalkan $g:[a, b] \rightarrow \mathbb{R}$ adalah fungsi monoton naik dan memenuhi 
$g(b)-g(a)=1$. Misalkan $x_{g}=\int_{a}^{b} x d g(x)$ dan $f:[a, b] \rightarrow \mathbb{R}$ adalah fungsi konveks, maka

$$
f\left(x_{g}\right) \leq M(f) \leq \frac{b-x_{g}}{b-a} f(a)+\frac{x_{g}-a}{b-a} f(b)
$$

Bukti: Tanpa mengurangi keumuman, asumsikan $f$ terdiferensialkan pada $(a, b)$ (Argumen mengenai asumsi ini dapat dilihat di (Cerone dan Dragomir, 2011) halaman 59). Karena $f$ adalah fungsi konveks, maka berdasarkan lema 2, untuk setiap $x \in[a, b]$ berlaku

$$
f(x) \leq f(a)+\frac{f(b)-f(a)}{b-a}(x-a)
$$

Dengan mengintegralkan kedua ruas ketaksamaan di atas dan membaginya dengan $g(b)-g(a)$ diperoleh

$$
M(f) \leq f(a)+\frac{f(b)-f(a)}{b-a}\left(x_{g}-a\right)=\frac{b-x_{g}}{b-a} f(a)+\frac{x_{g}-a}{b-a} f(b)
$$

Definisikan fungsi $u:[a, b] \rightarrow \mathbb{R}$ dengan aturan

$$
u(x)=[g(x)-g(b)] \int_{a}^{x} t d g(t)+[g(x)-g(a)] \int_{x}^{b} t d g(t)
$$

untuk setiap $x \in[a, b]$. Berdasarkan lema $6, u(x) \geq 0$ untuk setiap $x \in[a, b]$.

Definisikan fungsi $v:[a, b] \rightarrow \mathbb{R}$ dengan aturan

$$
v(x)= \begin{cases}f^{\prime}\left(x_{g}\right) & \text { jika } x=x_{g} \\ \frac{f(x)-f\left(x_{g}\right)}{x-x_{g}} & \text { jika } x \neq x_{g}\end{cases}
$$

Karena $f$ terdiferensialkan pada $(a, b)$, maka

$$
\lim _{x \rightarrow x_{g}} v(x)=\lim _{x \rightarrow x_{g}} \frac{f(x)-f\left(x_{g}\right)}{x-x_{g}}=f^{\prime}\left(x_{g}\right)=v\left(x_{g}\right)
$$

Akibatnya, $v$ kontinu pada $[a, b]$. Oleh karena itu, $u$ terintegralkan RiemannStieltjes terhadap $v$. Dengan menggunakan teknik integral parsial diperoleh

$$
\int_{a}^{b} u(x) d v(x)=[u(x) v(x)]_{a}^{b}-\int_{a}^{b} v(x) d u(x)
$$

Karena $u(a)=0$ dan $u(b)=0$, maka $\int_{a}^{b} u(x) d v(x)=-\int_{a}^{b} v(x) d u(x)$.

Berdasarkan lema $7, \int_{a}^{b} v(x) d u(x)=\int_{a}^{b} v(x)\left(x_{g}-x\right) d g(x)$ sehingga 


$$
\int_{a}^{b} u(x) d v(x)=\int_{a}^{b} f(x)-f\left(x_{g}\right) d g(x)=M(f)-f\left(x_{g}\right)
$$

Karena $u(x) \geq 0$ untuk setiap $x \in[a, b]$ dan $v$ adalah fungsi monoton naik, maka $\int_{a}^{b} u(x) d v(x) \geq 0$. Akibatnya, $M(f)-f\left(x_{g}\right) \geq 0$.

Jadi, terbukti bahwa $f\left(x_{g}\right) \leq M(f) \leq \frac{b-x_{g}}{b-a} f(a)+\frac{x_{g}-a}{b-a} f(b)$

Perhatikan bahwa ketaksamaan (4) dapat diperoleh dengan substitusi fungsi $g(x)=x$ pada ketaksamaan (5) sehingga ketaksamaan (5) merupakan perumuman ketaksamaan (4). Pemilihan fungsi $g$ yang tepat dapat digunakan untuk menghitung nilai rata-rata integral fungsi konveks yang terkait dengan rataan tertentu. Aplikasi ketaksamaan (5) dengan pemilihan fungsi $g$ tertentu diberikan pada bagian selanjutnya.

\subsection{Aplikasi Ketaksamaan Hermite-Hadamard terhadap Integral Riemann}

\section{Stieltjes.}

Salah satu contoh aplikasi penaksiran ketaksamaan Hermite-Hadamard terhadap integral Riemann-Stieltjes adalah penaksiran rataan pangkat dari $n$ buah bilangan real positif dengan rataan aritmatikanya yaitu $\bar{x}=\frac{1}{n} \sum_{i=1}^{n} x_{i}$, beserta nilai maksimum dan minimumya. Hal ini diberikan dalam teorema berikut:

Teorema 8 Misalkan $\left(x_{i}\right)_{i=1}^{n}$ adalah barisan $n$ buah bilangan real positif dengan rataan aritmatikanya adalah $\bar{x}=\frac{1}{n} \sum_{i=1}^{n} x_{i}$. Untuk $p \in \mathbb{R}$ dan $p \geq 1$ definisikan rataan pangkat dari $\left(x_{i}\right)_{i=1}^{n}$ sebagai $\left(\frac{1}{n} \sum_{i=1}^{n} x_{i}\right)^{1 / p}$.

Misalkan $m=\min \left\{x_{i}: i=1,2, \ldots, n\right\}$ dan $M=\operatorname{maks}\left\{x_{i}: i=1,2, \ldots, n\right\}$, maka

$$
\bar{x} \leq\left(\frac{1}{n} \sum_{i=1}^{n} x_{i}\right)^{1 / p} \leq\left(\frac{M-\bar{x}}{M-m} m^{p}+\frac{\bar{x}-m}{M-m} M^{p}\right)^{1 / p}
$$

Bukti: Misalkan semua bilangan yang berbeda dalam barisan $\left(x_{i}\right)_{i=1}^{n}$ diurutkan dari nilai yang terkecil ke nilai yang terbesar dan dinotasikan sebagai barisan $\left(y_{j}\right)_{j=1}^{k}$. Misalkan banyaknya bilangan bernilai $y_{j}$ pada barisan $\left(x_{i}\right)_{i=1}^{n}$ adalah $n_{j}$. 
Untuk setiap $j=1,2, \ldots, k$, definisikan $s_{j}=\sum_{h=1}^{j} n_{h}$.

Kemudian, definisikan fungsi $g:\left[y_{1}, y_{k}\right] \rightarrow \mathbb{R}$ dengan aturan

$$
g(x)= \begin{cases}0 & \text { jika } x=y_{1} \\ \frac{s_{j}}{n} & \text { jika } y_{j}<x \leq y_{j+1}, j=1,2, \ldots, k-2 \\ \frac{s_{k-1}}{n} & \text { jika } y_{k-1}<x<y_{k} \\ 1 & \text { jika } x=y_{k}\end{cases}
$$

Karena fungsi $g$ memiliki $m$ buah diskontinu loncat pada $\left[y_{1}, y_{k}\right]$ yaitu di titik $y_{1}, y_{2}, \ldots, y_{k}$, maka

$$
\begin{aligned}
x_{g}= & \int_{y_{1}}^{y_{k}} x d g(x) \\
= & y_{1}\left(\lim _{x \rightarrow y_{1}^{+}} g(x)-g\left(y_{1}\right)\right)+\sum_{j=2}^{k-1} y_{j}\left(\lim _{x \rightarrow y_{j}^{+}} g(x)-\lim _{x \rightarrow y_{j}^{-}} g(x)\right) \\
& +y_{k}\left(g\left(y_{k}\right)-\lim _{x \rightarrow y_{n}^{-}} g(x)\right) \\
= & y_{1} \frac{s_{1}}{n}+\sum_{j=2}^{k-1} y_{j}\left(\frac{s_{j}}{n}-\frac{s_{j-1}}{n}\right)+y_{k}\left(1-\frac{s_{k-1}}{n}\right) \\
= & \frac{1}{n} \sum_{j=1}^{k} y_{j} n_{j}=\frac{1}{n} \sum_{i=1}^{n} x_{i}=\bar{x}
\end{aligned}
$$

Definisikan fungsi $f(x)=x^{p}$ pada $\left[y_{1}, y_{n}\right]$, maka

$$
\begin{aligned}
M(f)= & \int_{y_{1}}^{y_{k}} f(x) d g(x) \\
= & f\left(y_{1}\right)\left(\lim _{x \rightarrow y_{1}^{+}} g(x)-g\left(y_{1}\right)\right)+\sum_{j=2}^{k-1} f\left(y_{j}\right)\left(\lim _{x \rightarrow y_{j}^{+}} g(x)-\lim _{x \rightarrow y_{j}^{-}} g(x)\right) \\
& +f\left(y_{k}\right)\left(g\left(y_{k}\right)-\lim _{x \rightarrow y_{n}^{-}} g(x)\right) \\
= & f\left(y_{1}\right) \frac{s_{1}}{n}+\sum_{j=2}^{k-1} f\left(y_{j}\right)\left(\frac{s_{j}}{n}-\frac{s_{j-1}}{n}\right)+f\left(y_{k}\right)\left(1-\frac{s_{k-1}}{n}\right) \\
= & \frac{1}{n} \sum_{j=1}^{k} f\left(y_{j}\right) n_{j}=\frac{1}{n} \sum_{i=1}^{n} f\left(x_{i}\right)=\frac{1}{n} \sum_{i=1}^{n} x_{i}^{p}
\end{aligned}
$$


Karena fungsi $f$ dan $g$ memenuhi hipotesis teorema 7, maka

$$
x_{g}^{p} \leq \frac{1}{n} \sum_{i=1}^{n} x_{i}^{p} \leq \frac{y_{k}-x_{g}}{y_{k}-y_{1}} y_{1}^{p}+\frac{x_{g}-y_{1}}{y_{k}-y_{1}} y_{k}^{p}
$$

Dengan mengambil akar pangkat $p$ dari setiap ruas ketaksamaan (7) dan kemudian substitusi $x_{g}=\bar{x}, y_{1}=m$, dan $y_{k}=M$ ke ketaksamaan (7) diperoleh ketaksamaan (6).

\section{KESIMPULAN}

Dengan menggunakan konsep integral Riemann-Stieltjes dapat didefinisikan nilai rata-rata integral Riemann-Stieltjes terhadap sebarang fungsi yang monoton naik dan selisih nilai di kedua ujung intervalnya positif . Dengan menggunakan nilai rata-rata integral Riemann-Stieltjes dapat dibuktikan suatu perumuman ketaksamaan Hermite-Hadamard yaitu ketaksamaan Hermite-Hadamard terhadap integral Riemann-Stieltjes. Salah satu manfaatnya adalah nilai rata-rata integral fungsi konveks dapat ditaksir dengan nilai fungsi di titik yang tidak hanya titik tengah interval. Salah satu contoh aplikasi langsung ketaksamaan (5) adalah penaksiran rataan pangkat dari $n$ bilangan real positif dengan rataan aritmatikanya. Agar diperoleh aplikasi yang lebih luas, sebaiknya syarat fungsi $g$ pada teorema 7 perlu diperlemah tetapi ketaksamaan (5) tetap berlaku.

\section{DAFTAR PUSTAKA}

Cerone P. dan Dragomir S.S, (2011), Mathematical Inequalities: A Perspective, Taylor and Francis Group, LLC.

Mitrinovic D. S. , Pecaric J. E. dan Fink A. M. (1993), Classical and New Inequalities in Analysis, Kluwer, Dordrecht.

Niculescu C. P. dan Pecaric J. E., (2010), The equivalence of Chebyshev's inequality with the Hermite-Hadamard inequality. Math. Reports, 12 (62), No. 2, 2010, pp. 145-156 
Niculescu C. P. dan Persson L.-E. (2006), Convex Functions and their Applications. A Contemporary Approach, CMS Books in Mathematics vol. 23, Springer-Verlag, New York.

Roberts A.W. and Varberg D.E. (1975), Convex Function, Academic Press, New York. 